\title{
POVOS INDÍGENAS EM CONTEXTOS DE DOMINAÇÃO: PROCESSOS IDENTITÁRIOS, TERRITÓRIOS E TRADIÇÕES DE CONHECIMENTO
}

\author{
Claudia MURA ${ }^{1}$ E EdVIGES MARTA IORIS ${ }^{2}$
}

Os estudos sobre grupos étnicos e suas interfaces com o território têm se constituído produções centrais da Antropologia, especialmente aquelas vinculadas ao desenvolvimento das pesquisas etnológicas e que se ocupam em compreender a força mobilizadora das fronteiras étnicas na construção e manutenção de alteridades, de organizações políticas e de reivindicações territoriais ${ }^{3}$. Não obstante tais temas acompanhem as problematizações antropológicas desde o início da disciplina, até meados da década de 1970 os povos e grupos etnicamente distintos ainda continuavam sendo abordados mesmo que por diferentes vieses - como unidades sociais isoladas, portadores de características culturais próprias que seriam resultantes de um pressuposto insulamento, os quais, todavia, estariam sendo ameaçados por um processo de assimilação e aculturação que os levaria a um gradativo e inexorável desaparecimento4 . Desde Malinowski (1976 [1922]), que lamentava já na saída de seu longo trabalho de campo pelo que compreendia estar em curso o "fim do objeto de estudo da Antropologia", aos estudos de aculturação dos anos 1950-60, ou estruturalistas dos anos 1950-70, os povos originários foram concebidos e descritos como unidades assentadas em instituições frágeis, conformadas no isolamento e ahistóricas, cujas distintividades inevitavelmente sucumbiriam frente ao avanço das sociedades modernas. Os processos de mudanças que sofriam, quando considerados, eram pensados como transição à sua inexorável supressão.

Os pressupostos holísticos e primordialísticos que norteavam esses estudos sustentavam, em sua maioria, a concepção de um "nativo" preso à sua cultura (pensada como autocontida, estática e atemporal), e confinado em um lugar ou território específico. Entre outros, tais pressupostos foram criticados de maneira exemplar por Appadurai (1988) e Wolf (2003; 2005), que demonstraram com inúmeros exemplos etnográficos como os grupos sociais analisados pelos antropólogos já haviam sido afetados, e continuavam sendo, pelo conhecimento de outros mundos em suas relações e trocas, mas principalmente pelo projeto

\footnotetext{
${ }^{1}$ Professora do Programa de Pós-Graduação em Antropologia Social da Universidade Federal de Alagoas.
}

${ }^{2}$ Professora do Programa de Pós-Graduação em Antropologia Social da Universidade Federal de Santa Catarina.

${ }^{3}$ Para um aprofundamento da discussão sobre as contribuições antropológicas nos estudos das terras indígenas e territórios ver Pacheco de Oliveira (2018).

${ }^{4}$ Ver: Wagley (1977); Galvão (1973[1955]); Wagley \& Galvão (1961); Schaden (1969). 
colonizador e a imposição de relações de poder desigual desde que se iniciou no século XVI. Tais pesquisas descortinaram as seculares hierarquizações geopolíticas embasadas na construção de "Outros", cujas diferenças, no discurso antropológico, afirmavam-se na produção de um distanciamento espaço-temporal que lhes negava a coetaneidade, isolando e imobilizando-os no tempo ou em estruturas inconscientes (Fabian, 2013).

Contudo, no final da década de 1960, a crítica às abordagens dos grupos étnicos como isolados sociais e culturais ganhava especial destaque com a publicação da renomada e já clássica introdução de Barth (2000c [1969]) ao livro Os grupos étnicos e suas fronteiras. Dessencializando a conformação dos grupos étnicos, a contribuição crítica do autor se destaca em apresentá-los simplesmente como um tipo organizacional, resultado da interação permanente com outros grupos que, em situações e contextos específicos, organizam socialmente a diferença cultural. A abordagem interacional, relacional e situacional proposta por Barth permitiu ao autor desnaturalizar a noção de "etnia" e deslocar a atenção sobre as construções identitárias, afastando-se de pressupostos e prévios conteúdos culturais, para direcionar o olhar sobre as "fronteiras" que os próprios agentes elegem em sua interação com distintos grupos ou povos, tornando-as a partir de então centrais na sua análise e tratadas como o principal objeto da antropologia.

Como diversos autores assinalaram, a atenção ao fenômeno étnico levantada por Barth representou uma mudança nas preocupações teóricas e metodológicas da Antropologia, ao retirar a conformação da alteridade do isolamento para compreendê-la na dinâmica situacional das interações sociais entre os grupos, e a partir das diferenças que os próprios sujeitos elegem como críticas (DEPRES, 1975). Adiante, retomando as contribuições de Barth, Amselle e M'Bokolo (2014) ressaltam ainda a abertura deixada pelo autor para pensar as relações entre grupos étnicos como relações de forças (p. 32) e a constituição de suas fronteiras como resultados do sistema colonial, embora não exclusivamente. Essas contribuições, entre outras, têm permitido o deslocamento do foco das análises conduzidas em diferentes contextos geográficos sobre a situação colonial - que não se limita ao período das colônias - para dar ênfase à violência e aos sistemas de dominação que permeiam as relações entre dominadores e dominados, ressaltando nesse sentido as interdependências que se estabeleceram em contextos históricos e políticos específicos marcados por distribuição desigual de poder entre as agências e os agentes envolvidos.

Na antropologia brasileira, pesquisadoras/es alinhadas/os com essa perspectiva teórica têm gerado um corpo de conhecimentos consistente com aportes teóricos significativos e originais para a disciplina, bem como incisivos na condução da elaboração das políticas de regulação fundiária dos povos indígenas e outros grupos étnicos, em contextos 
históricos diferentes que marcaram suas produções e atuações 5 . Neste sentido, produzindo uma revisão substancial do arcabouço conceitual da disciplina, atrelada a uma crítica rigorosa e consistente das práticas colonialistas que caracterizavam o trabalho dos antropólogos, têm enfatizado a indissociabilidade da pesquisa empírica da elaboração teórica e do compromisso ético com as coletividades desfavorecidas, bem como a necessidade da explicitação das posturas políticas das/os antropólogas/os para com elas. Ressalta-se nesta posição o alinhamento aos preceitos de compromisso ético e político da Antropologia em defesa dos povos originários firmados na Declaração de Barbados, há cinquenta anos, em 1971, assim como de elaborações de abordagens teórico-metodológicas que contemplem as situações de dominação e relações desiguais de poder, mas também o protagonismo e os modos de resistência indígena que têm assegurado a sua permanência na contemporaneidade e a atualização de sua alteridade (PACHECO DE OLIVEIRA, 2016).

Foi considerando a importância desses investimentos de pesquisa e de reflexão dos modos de produção do conhecimento antropológico que este dossiê buscou reunir artigos que abordassem processos que têm marcado política, econômica e territorialmente os modos de vidas dos grupos e povos que se diferenciam étnica e culturalmente, cujas análises considerassem o protagonismo e suas múltiplas formas de resistência (SCOTT, 1985, 1990; FERREIRA, 2013) examinando-os à luz das tradições de conhecimento, das transformações de cosmologias, bem como de quadros morais que orientam as experiências individuais e coletivas no estabelecimento e gerenciamento das relações intra e interétnicas. Pretendiase, assim, um conjunto de artigos resultados de pesquisas etnográficas e históricas que pensassem as unidades sociopolíticas em diferentes escalas _famílias, linhagens, associações entre outras - e os modos como estas conformações e alianças se efetivam no tempo e no espaço, podendo ou não extravasar o recorte territorial étnico, assim como as variações na elaboração e sistematização dos fluxos culturais oriundos de diferentes tradições de conhecimentos. As dinâmicas da organização social do conhecimento que marcam tais processos também têm recebido crescente atenção, atribuindo cada vez mais importância às bases articuladoras dos grupos étnicos, às identidades e às variações que se apresentam no gerenciamento, distribuição e hierarquização do conhecimento e que, em diferentes contextos históricos e políticos, definem específicas relações de poder.

Neste sentido, abrindo o dossiê, o artigo de João Pacheco de Oliveira Filho nos apresenta uma contribuição significativa ao urgente e necessário movimento auto reflexivo da disciplina, apresentando uma releitura da produção antropológica e da atuação de Darcy Ribeiro, no qual destaca os aspectos que evidenciam seu papel como intelectual e ator político, para traçar uma crítica original e profícua aos cientistas brasileiros na

\footnotetext{
${ }^{5}$ Entre a vasta literatura sobre esse tema citamos algumas referências: Cardoso de Oliveira (1981), Pacheco de Oliveira $(1988,2016)$, Almeida (2008); Souza Lima (1995), O'Dwyer (2011), Leite (2008).
} 
contemporaneidade. Pacheco de Oliveira contextualiza parte da produção de Darcy Ribeiro, em especial Os Índios e a Civilização, e sua atuação no SPI, vinculando-a ao contexto da década de 1950 e ao diálogo com outros antropólogos brasileiros e indigenistas da época, especialmente, Roberto Cardoso de Oliveira. O autor chama a atenção sobre as propostas e noções teóricas de Darcy Ribeiro, que visavam o aprofundamento dos estudos das interações entre os indígenas e as frentes de expansão em busca de uma compreensão da mudança sociocultural das populações indígenas. Destaca, nesta direção, a crítica de Ribeiro ao culturalismo e às teorias da aculturação e insere sua contribuição nos estudos sobre contato interétnicos, aproximando-a as de Fredrik Barth sobre a etnicidade, então elaboradas contemporaneamente às suas.

Não obstante reconheça os vários alcances da produção de Darcy Ribeiro, Pacheco de Oliveira, por outro lado, assinala também os limites e/ou contradições (ou, nos termos do próprio autor, "desvios de rumo") das suas contribuições para a elaboração de uma perspectiva processualista e historicizante de maior alcance para compreender os processos de mudança dos povos indígenas a que se propunha. Segundo Pacheco de Oliveira, estes limites residiriam "nas concepções evolucionistas subjacentes à obra do autor" que se mantinham, ainda compreendendo as unidades sociais em contato interétnico a partir de diferentes estágios evolutivos. No entanto, remetendo-as às preocupações que o norteavam e à ideologia indigenista da época que vivenciou, coloca em evidência a importância da sua então inovadora argumentação que visava também renovar a administração pública e construir caminhos para o reconhecimento dos direitos indígenas. A sua análise salienta ainda a proposta de Ribeiro para antropologia brasileira, que se insere no movimento de descolonização da pesquisa, o qual buscava incentivar a construção de "um padrão acadêmico e profissional próprio, que permitisse conjugar o exercício da ciência com uma atitude ética e posicionada, aspectos que continuam a ser inspiradores para a antropologia e o indigenismo atual" (p. 22).

Afinados com a abordagem processualista contemporânea, que aproxima a Antropologia à História, proposta por Pacheco de Oliveira $(1999,2004,2016)$ e que acompanha o movimento de descolonização da disciplina, os trabalhos que se encontram reunidos neste dossiê refletem os esforços analíticos das/dos autoras/es para a compreensão de processos e dinâmicas socioculturais e políticas que envolvem grupos indígenas inseridos em contextos de dominação, conduzidos a sucessivos processos de territorialização, calcados em lógicas colonialistas que visam perpetuar a secular marginalização dos indígenas, os quais são submetidos a ações de extermínio e tutela (PACHECO DE OLIVEIRA, 2016); investidas que visam reduzir a riqueza e diversidades de experiências, de formas de organização social e elaborações culturais, percebidas como obstáculos à construção e reprodução do Estado-nação. As contribuições ressaltam, nesse 
sentido, a complexa e violenta relação com agências anti-indígenas, bem como com os órgãos do Estado.

Durante o período colonial, a dominação dos povos indígenas se exerceu através de políticas tutelares, mediante o confinamento de grandes contingentes da sua população nos aldeamentos gerenciados por missionários de diferentes ordens religiosas. O ordenamento territorial que vigorava favorecia a conformação de um latifúndio excludente, que se apropriava dos territórios indígenas e os submetiam como mão de obra. Esse primeiro processo de territorialização (PACHECO DE OLIVEIRA, 2004) foi marcado pela condução compulsória de parcelas de diferentes grupos indígenas aos aldeamentos e pelas políticas de mistura forçada, recrudescidas, em seguida, com a extinção dos aldeamentos e a conseguinte dispersão das famílias indígenas. O segundo processo de territorialização, no começo do século XX, se realizou sob a marca da atuação do Serviço de Proteção aos Índios (SPI), órgão encarregado da tutela dos povos indígenas que, em 1967, cedeu lugar à Fundação Nacional do Índio (FUNAI). Embora a dominação das populações indígenas tenha se perpetuado, a nova "situação histórica" (PACHECO DE OLIVEIRA, 1988) viabilizou a reivindicação do reconhecimento dos vínculos étnicos e dos direitos territoriais por parte de inúmeros grupos indígenas, processo que se amplificou após a promulgação da Constituição de 1988.

Neste sentido, é fundamental considerar o alerta que Pacheco de Oliveira (2004) nos faz de que os processos de territorialização não devem ser entendidos como um movimento de mão única, apenas como uma imposição do Estado, mas que em suas análises deve-se ter presente igualmente a agência dos indígenas para manter sua alteridade não obstante a violência sofrida ao longo do projeto colonizador. As instituições, estratégias e concepções indígenas são atualizadas no específico contexto social e, ao considerar as diferentes escalas (familiar e étnica, bem como regional, nacional e internacional) adquirem múltiplos sentidos, o que nos leva a dirigir a atenção às variações e a nos afastar de abordagens totalizadoras e generalizantes, e compreender inclusive em unidades mais capilares, de grupos domésticos, a reelaboração da memória sobre seus espaços territoriais e a moldagem das tradições de conhecimento de seus ancestrais. Nessa direção, as contribuições deste dossiê, nos contextos focados, salientam as interpretações dos eventos que os indígenas vivenciaram, a capacidade de articulação política, de adaptação e de significação de seus territórios e de seus repertórios cosmológicos com base nas suas experiências, formas de conhecer e gerenciar o conhecimento.

Exceto pelo artigo de Amanda Jardim, que aborda os Xakiabrá no norte mineiro, a maioria das/os autoras/es dos textos do dossiê trabalha com grupos indígenas no Nordeste, região onde, desde o começo do século passado, tem se conformado expressivo palco de sucessivos processos de construção e afirmação da identidade étnica de grupos indígenas 
em todos os estados da região. No entanto, processos de reconhecimento e afirmação identitária não são exclusivos dos indígenas do Nordeste, mas têm ocorrido também nas várias regiões do País, seja na Amazônia (IORIS, 2014, 2017, 2018; VAZ, 2010), ou no Sudeste, em Minas Gerais, como nos mostra neste dossiê o texto do artigo de Amanda Jardim sobre os Xakiabrá, os quais estão fortemente atrelados não só à reafirmação da memória étnica de seus pertencimentos históricos, mas também às reivindicações territoriais desses povos. Nesse sentido, os conflitos fundiários se tornam o pano de fundo das análises das/os autoras/es aqui reunidos/as, constituindo o principal impulsionador das fronteiras identitárias.

A etnicidade, como as contribuições deste dossiê reafirmam, não decorre das descontinuidades culturais empiricamente observáveis a priori, exigindo-se uma análise etnográfica dos contextos que a impulsiona, e da reorganização social e reelaboração cultural protagonizada por específicos e concretos atores sociais. Cabe ressaltar que a fronteira étnica se contrapõe à dinâmica dos fluxos culturais (HANNERZ, 1997) que a atravessam e que possibilitam interpretações e trajetórias diferenciadas para os membros e famílias dos atuais grupos étnicos, os quais, no decorrer do tempo, criaram vínculos com outros grupos, inclusive com aqueles que não se diferenciam etnicamente e com os quais apresentam semelhanças de modelos culturais. A fronteira étnica, um entre outros princípios de organização social da cultura, controla e canaliza os fluxos, gerando a diferença de modelos culturais em contraste com outros. No entanto, os artigos aqui reunidos focam especialmente as bases articuladoras da organização dos grupos étnicos: as unidades familiares e os grupos domésticos, cujas identidades e conhecimentos mostraram-se bem mais resistentes faces ao compulsório processo de apagamento das fronteiras étnicas que os grupos indígenas sofreram em outros contextos históricos. As trajetórias familiares podem apresentar variações significativas na sistematização de conhecimentos e valores que, em determinadas circunstancias, levam à constituição de outras fronteiras étnica, como no caso das fissões de grupos indígenas ${ }^{6}$. Esses aspectos são importantes para a análise das várias formas de organizar a cultura e produzir a diferença, como no caso dos processos abordados por Andrade e Palitot, que focam a constituição e manutenção da tradição de conhecimento de dois grupos indígenas no Nordeste, região de antiga colonização perpassada por fluxos culturais oriundos de tradições de conhecimento da Europa, da África e da América.

Alguns autores ${ }^{7}$ já alertaram que as noções de sincretismo e de mistura empregadas para abordar tais processos, acabariam reiterando a ideia da existência de prévios isolados e/ou totalidades culturais fechadas, sendo necessário compreender como os elementos

\footnotetext{
${ }^{6}$ Ver o caso dos guaranis analisado por Mura e Silva (2011), Mura F. (2019).

${ }^{7}$ Ver: Mura F. e Silva (2011) e Mura C. (2013). 
culturais são organizados pelos grupos para dar sentido à experiência e à existência das pessoas em contextos históricos concretos, marcados por específicas relações de poder; em outras palavras, as tradições de conhecimento são mais bem definidas em virtude da atuação dos atores sociais que possibilitam uma maior ou menor propagação delas, do que por seus conteúdos ou repertórios ideativos. Com efeito, as mais recentes contribuições de Barth (1987, 1993, 2000b), especialmente nos estudos sobre tradições de conhecimento em Bali e na Nova Guiné, deslocam o foco da fronteira étnica versus outras formas duradouras de organizar a cultura. Nessas pesquisas, Barth ressaltou que o processo de construção da diferença não se baseia apenas na demonstração de sinais diacríticos, com bem apontou Palitot em seu artigo deste dossiê. Como no caso dos Pankararu (MURA, 2013, 2017), a produção da diferença abrange a própria organização social do Cosmo, ou seja, a articulação das entidades e a repartição de competências das práticas rituais a elas vinculadas entre grupos étnicos, bem como entre grupos rituais do mesmo grupo étnico. A atenção recai sobre o contraste entre "economias informacionais" (BARTH, 2000b, p. 146) que permitem uma maior ou menor propagação das tradições de conhecimento e moldam diversamente as expressões culturais, embora os itens culturais em fluxo circulem em vastas regiões. Esse contraste é produzido desde um ponto de vista moral por atores sociais que gozam da legitimidade na atribuição de sentidos às práticas cotidianas dos membros que aderem a essa tradição e que fundamentam sua forma de viver, sujeita a adaptações em virtude do contexto social, histórico e territorial que experienciam. As tradições de conhecimento, conforme apontado por Barth, transcendem as realidades locais e são transversais aos grupos étnicos, permitindo formas de pluralismo cultural como o caso de Bali por ele analisado (BARTH, 2000a). Nesse sentido, as cosmologias são abordadas processualmente, como uma "viva tradição de conhecimento e não como um conjunto de ideias abstratas consagradas em representações coletivas" (BARTH, 1987, p.87, tradução das autoras), que nos permite, assim, olhar para os eventos como incidentes sobre o próprio processo de moldagem da tradição e da cultura realizada pelos atores sociais.

Nesse sentido, as reflexões das/os pesquisadoras/es aqui reunidas, sobre esse conjunto de aspectos e dinâmicas, realçam o protagonismo dos indígenas nas diferentes configurações sociais focadas, em suas mobilizações por reconhecimento e direitos territoriais, mas também na reelaboração da memória, das histórias de seus povos e de seus núcleos domésticos, para se contrapor às narrativas oficiais que têm excluído não só o seu protagonismo e participação nas economias políticas locais, mas também a sua própria existência, produzindo sistemáticos apagamentos dos seus registros. Assim, como principais artífices na construção de novos regimes de memória (PACHECO DE OLIVEIRA, 2016), que ressaltam suas existências e protagonismos, os indígenas reconstroem na contemporaneidade uma versão alternativa àquela que os têm suprimido da narrativa 
historiográfica oficial, estabelecendo novas bases para pautar suas demandas nas mesas de negociação do poder. Como se há destacado, nestes novos regimes de memória é importante que se considere que "ações culturais e performances rituais constituem modos de retrabalhar a memória e reescrever a história, mas também de empoderamento e de expressão da sua alteridade" (IORIS, 2018, p.5).

Com preocupações semelhantes, o texto de Mariana Albuquerque Dantas nesse dossiê, fruto de uma importante pesquisa documental, apresenta uma reflexão esclarecedora sobre a política dos índios de Cimbres, Pernambuco, nas primeiras décadas do século XIX, revelando sua complexidade e o acurado posicionamento dos indígenas na relação de interdependência com outros sujeitos políticos. Com os pressupostos metodológicos da micro-história e adotando o diálogo entre História e Antropologia Política, a autora mostra as estratégias elaboradas pelos indígenas, relacionadas aos contextos fundiários e aos conflitos políticos local, regional e nacional, bem como a especificidade da interpretação e da conexão das ideias e conceitos que, nesse então, vigoravam, com o intuito de alcançar seus objetivos, especialmente o acesso e administração do território. Ressalta ainda que a migração para Alagoas, além de ter sido uma das estratégias adotadas pelos índios de Cimbres quando as ameaças e violências se agudizavam, oportunizou um fluxo de pessoas entre as duas províncias. Esses deslocamentos entre Pernambuco e Alagoas, destaca Dantas, se tornaram um importante elemento da formação das identidades coletivas dos indígenas, impulsionando a reelaboração dos fluxos culturais e das relações com o território. Ao problematizar as classificações e julgamentos nas fontes analisadas, Dantas mostra rigorosamente a ação política dos indígenas na defesa de interesses comuns e a reafirmação da própria identidade coletiva, apresentando-os como sujeitos ativos e participantes da escrutinada dinâmica local e da construção do Brasil Imperial, no recorte temporal focado.

O artigo de Wemerson Ferreira da Silva, por sua vez, concentra-se na análise do incipiente processo de construção da identidade étnica de três famílias extensas XukuruKariri em Taquarana, no agreste de Alagoas. O autor se debruça sobre as experiências que marcaram a trajetória dessas famílias, uma comunidade política local fundada nas primeiras décadas do século passado e inaugurada por uma indígena Xukuru-Kariri que, junto a um irmão, se deslocou das terras de um extinto aldeamento para a então chamada Fazenda Nóia, em busca de terra, trabalho e moradia. Trata-se de uma condição vivenciada por muitos indígenas que, após a extinção dos aldeamentos e por meio das políticas forçadas de dissolução dos grupos étnicos no Nordeste, tem impelido uma considerável mobilidade de parcelas da população indígena que neles residiam. No entanto, como bem aponta o autor, sustentado em uma etnografia cuidadosa, a dissolução da fronteira étnica de muitos grupos não resultou no apagamento de comunidades políticas locais ancoradas em relações de parentesco, com específicas cosmologias e moralidades, alimentadas na interação entre 
grupos domésticos espalhados em localidades, inclusive distantes, de um território mais amplo. Silva destaca os vínculos de parentesco, políticos e rituais que essas famílias em Taquarana mantiveram com os Xukuru-Kariri na aldeia Fazenda Canto, em Palmeira dos Índios, cujo território e identidade foram reconhecidos na década de 1950. O autor chama a atenção para a importância do apoio e da atuação dos "parentes" na recente reivindicação identitária e territorial dos indígenas em Taquarana e analisa a dinâmica territorial nesse contexto, a reelaboração de seu passado, bem como o processo de etnificação de suas expressões culturais.

Nesta direção, o texto de Silva dialoga muito proximamente com o artigo de Amanda Jardim, que se debruça sobre as relações entre mobilidade e territorialidade dos indígenas Xakriabá. Nele, a autora escolheu uma abordagem biográfica e apresenta as trajetórias de membros de uma família extensa através das narrativas de dois irmãos: Célia e Edgar. Na descrição e análise, Jardim opera com as noções "viver o" e "estar no" território que despontam nas narrativas desses interlocutores, sem a pretensão de apresentá-las como operantes na maioria das famílias desse povo indígena, embora elas possam ter semelhantes trajetórias marcadas pela mobilidade. A autora analisa o histórico do território Xakriabá, no norte de Minas Gerais, no município de São João das Missões, que compreende duas áreas contíguas, homologadas em momentos diferentes (1987 e 2003). Ressalta que os Xakriabá obtiveram o reconhecimento de sua identidade indígena apenas na década de 1970 e que, como outros povos indígenas - inclusive os que são abordados neste dossiê - estiveram envolvidos em fortes conflitos fundiários e sofreram a suspeição de suas identidades, sendo percebidos e tachados como "remanescentes". A autora apresenta um diálogo profícuo com pesquisas desenvolvidas junto a outros povos indígenas as quais destacam a construção das memórias relativas ao território. Na análise das narrativas em foco, Jardim evidencia que as referências aos parentes das gerações ascendentes são acionadas com múltiplos intuitos, especialmente para reafirmar o pertencimento étnico e o específico significado atribuído ao território. O vínculo estabelecido entre os entes vivos e finados com o território de origem, lugar de moradia dos ancestrais, e a "luta" por ele, significam "viver o" território, mesmo quando se está fora dele. Nesse sentido, a análise de Jardim mostra como a mobilidade dos Xakriabá envolve um "retorno" de dupla natureza: uma volta para estar no território e uma volta para se afirmar como indígena, engendrada na noção de "viver o território".

O artigo de Estevão Martins Palitot, por sua vez, apresenta uma análise sobre discursos e imagens que se encontram nos documentos produzidos no decorrer de duas perícias judiciais antropológicas nas terras indígenas potiguara, no litoral norte da Paraíba, entre os quais o autor ressaltou disputas em suas formulações, sobre o que identificou como 
"regimes de memória"8. Assim, destacando os discursos e as imagens oficiais que atravessam esses regimes de memória, assinala como estes visam reiterar o exotismo e o primitivismo, produzindo obstáculos e impedimentos para o reconhecimento dos Potiguaras - então, tachados de "remanescentes" ou de "Falsos índios" - e dos seus direitos territoriais. Em contraste com esses discursos e imagens exotizantes e preconceituosas, o autor apresenta a memória elaborada pelos Potiguaras sobre seu território, um conjunto de narrativas que se distancia sensivelmente dos registros e documentos históricos, e que resulta de uma interpretação específica dos indígenas sobre os acontecimentos vivenciados desde o passado colonial, e a sua atualização nas relações de dominação contemporâneas.

A análise do Palitot não se limita às narrativas sobre a memória e, desse modo, através de uma rica etnografia, aborda as interações dos indígenas com os ambientes do seu cotidiano, marcados por relações econômicas, ecológicas e cosmológicas. Atribui especial importância aos grupos domésticos que vivem em diferentes ambientes povoados por seres humanos e não-humanos e os necessários conhecimentos e cuidados para com eles nas atividades cotidianas, bem como o papel dos especialistas rituais que detêm competências diferenciadas para lidar com eles. Um aspecto de relevante importância que desponta na argumentação do autor é que a cosmologia não é um conjunto de elementos e representações em abstrato, mas é definida e promovida para fundamentar e orientar a forma de viver das pessoas e é adaptada aos contextos sociais, históricos, ecológicos e territoriais em que atuam. É nesse sentido que o autor, já nas conclusões, chama a atenção sobre a necessidade de analisar as diferentes formas com que os grupos domésticos indígenas articulam as tradições de conhecimento, produzem sentidos para suas vidas, geram e comunicam a própria diferença e a vinculam ao seu território, o qual, nas palavras do autor "é ao mesmo tempo recurso econômico, patrimônio coletivo e universo simbólico de referência" (p. 132). A diferença, alerta o autor, não deve ser reduzida a um conjunto de sinais diacríticos comunicados "рага fora", mas é fundamentada em saberes e práticas elaborados pelos atores sociais e que dão forma aos estilos de vida dos indígenas e à sua relação com o território.

Por fim, o artigo de Lara Erendira Almeida de Andrade se propõe a uma reflexão sobre as redes rituais tecidas pelas famílias do grupo indígena Kapinawá, em Pernambuco, e sobre a reelaboração dos rituais em um especifico contexto experiencial, entre as décadas de 1980 e 2010. Toma em consideração o processo de territorialização que os Kapinawá vivenciaram, a reivindicação da própria identidade e da regularização do território, destacando a importância da circulação dos indígenas para participar dos rituais, a constituição da rede que viabilizou a articulação e a aliança política entre as famílias e

\footnotetext{
${ }^{8}$ Para um aprofundamento da noção de "regime de memória" ver Fabian (2001) e Pacheco de Oliveira (2016).
} 
alimentou o sentimento de pertencimento ao grupo étnico. Embasa sua análise retomando as contribuições críticas de Barth sobre etnicidade e cultura (2005), com o intuito de ressaltar o processo de etnificação dos rituais elevados a sinais diacríticos. Assim como o texto de Wemerson Ferreira da Silva, que aborda o caso dos Xukuru-Kariri em Taquarana, o de Andrade também lança luz sobre as adaptações e reelaborações culturais dos atores sociais na produção de suas fronteiras étnicas e se somam a outras produções que têm dirigidos a atenção aos processos de etnificação ${ }^{9}$ das expressões culturais nos contextos de reivindicações identitárias, especialmente na região Nordeste. A autora argumenta acerca da elaboração da tradição de conhecimento dos Kapinawá, ressaltando o papel desenvolvido pelos médiuns no ritual do toré e pelos cantadores profissionais no ritual samba do coco, especialistas na comunicação com as entidades do Cosmo. Mostra, assim, como o acesso a esses conhecimentos não é permitido a todos e sinaliza a existência de uma específica distribuição da cultura que, no contexto em foco, leva a viver e significar os rituais de forma diferente entre seus participantes. No entanto, ressalta a leitura específica das correntes culturais em fluxo e a moldagem particularizada da tradição de conhecimento dos Kapinawá.

Antes de encerrar esta apresentação, cabem algumas considerações sobre a situação dos povos indígenas neste momento, em plena pandemia, sob um governo que abertamente tem declarado desejos de seu extermínio, e tem atuado nessa direção. No atual contexto brasileiro, os povos indígenas são alvo de ataques cada vez mais violentos, marcados por invasões às suas terras, por queimadas, perseguições e tentativas diárias de retiradas dos direitos essenciais à sua sobrevivência e reprodução, conquistados após longas lutas e garantidos pela Constituição de 1988. Perante tais continuados ataques, os povos indígenas, longe de uma postura submissa e passiva, têm construído estratégias de articulação e atuação política criativa e incisiva, agregando e respeitando suas especificidades na construção de uma agenda de ações com suas parcerias em nível local, nacional e internacional, recusando a condição de tutelados nas margens e exigindo, cada vez mais, a inserção de seus representantes nas diferentes esferas e instâncias governamentais.

A participação ativa dos indígenas na história do Brasil - embora sempre invisibilizada e colocada à margem pelos que os consideraram e ainda hoje os consideram um obstáculo ao "progresso" do Estado-Nação (conceito atrelado à ideia de soberania territorial que exclui as vítimas do colonialismo), com o intuito de explorá-los - sempre foi presente, como as pesquisas aqui reunidas e muitas outras já demostraram. Ao invés de abordar as

\footnotetext{
${ }^{9}$ Ver entre outros Arruti $(1995,2002)$, Mura (2013), Peres (2013).
} 
trajetórias dos povos indígenas como histórias separadas ou paralelas à história do Brasil ${ }^{10}$, reiterando posturas colonialistas que os relegam à condição de outredad distante, o que equivale a negar-lhes a história, urge considerá-las partes integrantes e fundamentais desse processo.

\section{REFERÊNCIAS}

ALMEIDA, Alfredo Wagner Berno de. Terra de quilombo, terras indígenas, "babaçuais livre", "castanhais do povo", faixinais e fundos de pasto: terras tradicionalmente ocupadas. Manaus: pgscaufam, 2008.

APPADURAI, Arjun. Putting hierarchy in its place. Cultural Anthropology, v. 3, n. 1, p. 36-49, 1988.

AMSELLE, Jean-Loup. M'BOKOLO, Elikia (Org.). Pelos meandros da etnia: etnias, tribalismo e Estado em África. Luanda- Angola- Portugal: Edições Mulemba e Pedago, 2014.

ARRUTI, José Maurício P. A. Morte e vida do Nordeste indígena: a emergência étnica como fenômeno histórico regional. Estudos históricos, Rio de Janeiro, v. 8, n. 15, p. 57-94, 1995.

. De como a cultura se faz política e vice-versa: Sobre religiões, festas, negritudes e indianidades no Nordeste contemporâneo. Texto apresentado ao "IV Ciclo NAÇÃO E REGIÃO - Brasil 500 anos Experiência e Destino" promovido pela FUNART / UERJ e UENF, 2002.

BARTH, Fredrik. A análise da cultura nas sociedades complexas. In: variações antropológicas. Rio de Janeiro: Contra Capa, 2000a.p. 107-140. 0 guru, o iniciador e outras

Balinese Worlds. Chicago: The University of Chicago Press, 1993.

. Cosmologies in the making. A generative approach to cultural variation in Inner New Guinea. Cambridge: Cambridge University of Chicago, 1987.

. Etnicidade e o conceito de cultura. Antropolítica, Niterói, v. 2, n. 19, p. 15-30, 2005.

. 0 guru e o iniciador: transações de conhecimento e moldagem da cultura no sudeste da Ásia e na Melanésia. In: Capa, 2000b. p. 141-166.

Os grupos étnicos e suas fronteiras. In: 0 guru, 0 iniciador e outras variações antropológicas. Rio de Janeiro: Contra Capa, 2000c [1969]. p. 25-68.

CARDOSO DE OLIVEIRA, Roberto. 0 Índio e o Mundo dos Brancos. São Paulo: Editora Pioneira, 1981.

DEPRES, Leo A. Toward a Theory of Ethnic Phenomena. In: DESPRES, L. (Ed.). Ethnicity and Resource Competition in Plural Societies. Paris: Mouton Publishers, 1975. p. 187-207.

\footnotetext{
${ }^{10}$ Nesse sentido, ver a crítica à etnohistória elaborada por Pacheco de Oliveira (2016). 
FABIAN, Johannes. 0 tempo e o outro. Como a antropologia estabelece seu objeto. Rio de Janeiro: Vozes, 2013.

. Ethnology and history. In: .Anthropology with an atitude: critical essay. Stanfors: Stanford University Press, 2001.p. 70-86.

FERREIRA, Andrey Cordeiro. Tutela e resistência indígena: etnografia e história das relações de poder entre os Terena e o Estado brasileiro. São Paulo: Editora da Universidade de São Paulo, 2013.

GALVÃo, Eduardo. Santos e Visagens: Um estudo da vida religiosa de Itá. São Paulo: Cia Editora Nacional, 1973[1955].

HANNERZ, Ulf. Fluxos, fronteiras, híbridos: palavras-chave da antropologia transnacional. Mana, Revista do PPGA/UFRJ, v. 3, n. 1, p. 7-39, 1997.

IORIS, Edviges M. Uma Floresta de Disputas: Conflitos sobre espaços, recursos e identidades sociais na Amazônia. Florianópolis: Editora UFSC, 2014.

IORIS, Edviges M. "De ruínas e fragmentos: narrativas e reflexões indígenas na reconstrução do passado e das identidades étnicas". In: Ricardo Verdum; Edviges M loris (Org.). Autodeterminação, autonomia territorial e acesso à justiça: povos indígenas em movimento na América Latina. Rio de Janeiro: Associação Brasileira de Antropologia (ABA), 2017. p. 229-251.

IORIS, Edviges M. Memory regimes, struggles over resources and ethnogenesis in the Brazilian Amazon. Vibrant, v. 15, n. 2, May-August 2018. p. 1-23.

LEITE, Ilka Boaventura. 0 Projeto Político Quilombola: Desafios, Conquistas e Impasses Atuais. Estudos Feministas, Florianópolis, v. 16, n. 3, p. 965-977, 2008.

MALINOWSKI, Bronislaw. Argonautas do Pacífico Ocidental. São Paulo: Abril Cultural, 1976 [1922].

MURA, Claudia. Todo mistério tem dono! Ritual, política e tradição de conhecimento entre os Pankararu. Rio de Janeiro: Contra Capa, 2013.

- A organização social do Cosmo: processos político-cosmológicos e tradição de conhecimento entre os Pankararu. In: Alexandra Barbosa da Silva; Baltazar Macaíba de Souza; Fabio Mura; Ruth Henrique. (Org.). Território, Ambiente, Identidade e Poder: reflexões a partir de múltiplas perspectivas. João Pessoa: UFPB, 2017. p. 81-102.

MURA, Fábio. "Á procura do "bom viver": território, tradição de conhecimento e ecologia doméstica entre os Kaiowa. Rio de Janeiro, Associação Brasileira de Antropologia, 2019.

MURA, Fabio; SILVA, Alexandra Barbosa da. Organização doméstica, tradição de conhecimento e jogos identitários: algumas reflexões sobre os povos ditos tradicionais. Raízes, Campina Grande, v. 33, n.1, p. 96-117, 2011.

O'DWYER, Eliane Cantarino. Etnicidade e direitos territoriais no Brasil contemporâneo. Iberoamericana, v. 11, n. 42, p. 111-126, 2011. 
PACHECO DE OLIVEIRA, João. Uma etnologia dos índios misturados? Situação colonial, territorialização e fluxos culturais. In: (Org.) A viagem da volta: etnicidade, política e

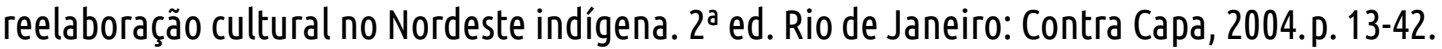

“0 Nosso Governo": Os Ticuna e o Regime Tutelar. São Paulo: Marco Zero/CNPq, 1988.

Ensaios em Antropologia Histórica. Rio de Janeiro: Editora UFRJ, 1999.

0 nascimento do Brasil e outros ensaios: "pacificação", regime tutelar e formação de alteridades. Rio de Janeiro: Contra Capa, 2016.

. Introduction: Fighting for lands and reframing the culture. Vibrant, v. 15, n. 2 | May - August, 2018. p. 1-21.

PERES, Sidnei. Política da identidade: 0 associativismo e movimento indígena no Rio Negro. Manaus: Valer, 2013.

SCHADEN, Egon. Aculturação indígena: ensaio sobre fatores e tendências da mudança de tribos índias em contato com o mundo dos brancos. São Paulo: Pioneira, 1969.

SCOTT, James C. Weapon of the Weak: Everyday Forms os Peasant Resistance. New Haven and London: Yale University Press, 1985.

Domination and the Arts of Resistance: Hidden Transcripts. New Haven and London: Yale University Press, 1990.

SOUZA LIMA, Antonio Carlos. Um Grande Cerco de Paz. Poder tutelar, indianidade e formação do Estado no Brasil. Petrópolis, Vozes, 1995.

VAZ, Florêncio de Almeida. A emergência étnica de povos indígenas no Baixo Rio Tapajós, Amazônia. Tese (Doutorado em Antropologia) - Universidade Federal da Bahia, Salvador, 2010.

WAGLEY, Charles. Welcome of Tears: The Tapirapé Indians of Central Brazil. Waveland Press, 1977.

WAGLEY, Charles; GALVÃo, Eduardo. Os Índios Tenetehara: Uma cultura em transição. Rio de Janeiro: Ministério da Educação e Cultura,1961.

WOLF, Erik. Europa y la gente sin história. Mexico: FCE, 2005.

Inventando a sociedade. In: FELDMAN-BIANCO, Bela e LINS, Gustavo Ribeiro (Orgs)

Antropologia do Poder: Contribuições de Eric R. Wolf. São Paolo: E. Unicamp, 2003. p. 307-324. 